\title{
Duplo, imagem e reino do simulacro: "William Wilson", de Edgar Allan Poe
}

\section{Maria Cristina Franco Ferraz e Louise Ferreira Carvalho}

\section{Resumo}

Partindo do conto "William Wilson", de Edgar

Allan Poe, 0 artigo explora o tema do Duplo e seus desdobramentos nos campos da subjetividade e da imagem no século XIX. A obsessão pelas sombras perversas no período moderno repercute certas incertezas instauradas no pensamento europeu, tais como a crise do modelo de identidade herdado do platonismo, a deformação da figura humana, a emergência da psicanálise. Evidencia, em suma, a força da ameaça à coesão do eu. Como eixo investigativo, busca-se relacionar o tema ao gesto antiplatônico e à filosofia antimetafísica, expressos nas leituras do simulacro e da máscara efetuadas por Deleuze e Nietzsche. Propõe-se explorar trechos do conto que ressaltam a potência do falso e colocam em suspeição certas heranças platônicas no 0cidente.

\section{Palavras-Chave}

Duplo. Regime do simulacro. Filosofia antimetafísica.

\section{Maria Cristina Franco Ferraz}

I mcfferraz@hotmail.com

Professora Titular da Escola de Comunicação da Universidade Federal do Rio de Janeiro - UFRJ, Brasil. Doutora em Filosofia pela Universidade de Paris I-Sorbonne, realizou três estágios pós-doutorais em Berlim. É Mestre em Letras pela Pontifícia Universidade Católica do Rio de Janeiro - PUCRJ, Brasil, e pesquisadora do CNPq.

\section{Louise Ferreira Carvalho}

| louisecarvalho1@hotmail.com

Mestranda do Programa de Pós-graduação em Comunicação e Cultura da Universidade Federal do Rio de Janeiro - UFRJ, Brasil. É bolsista da FAPERJ.
Publicado em 1834, o conto "William Wilson", do escritor norte-americano Edgar Allan Poe, fornece um material instigante para se investigarem certas visadas antimetafísicas que se insinuaram na filosofia ocidental e questões identitárias que assombraram o mundo moderno. 0 título e nome "próprio" William Wilson oferece, de saída, valiosas pistas: $W$ é uma letra que exprime, em sua própria materialidade, um Duplo ${ }^{1} ;$ como se não bastasse, o fragmento "wil" duplica-se ainda literalmente no nome e no sobrenome, repercutindo-se como sombra, reflexo e eco sonoro. 0 tema do Duplo se introduz, portanto, desde o título, de modo enfático, em várias camadas e níveis. Além disso, a primeira frase do conto, "deixem-me chamar, por ora, William Wilson" (POE, 2008, p. 234)², corrói o vínculo usualmente imediato entre nome próprio e identidade, instaurando um jogo de máscaras que torna a oposição entre verdadeiro e falso indecidível. 0 próprio conto parece, assim, indicar certos caminhos de leitura e de investigação. Sigamos a via apontada, tecendo uma rede de relações entre o texto e 0 tema do Duplo, a fim de discutir a crise nos modos de subjetivação moderna. 
Para podermos dimensionar tal crise em meio ao fervilhar do turbilhão moderno, faz-se necessário recuar, inicialmente, ao que aí parecia se fraturar: a cisão radical corpo/alma proposta por René Descartes, em suas Meditações metafísicas. No século XVII, o cartesianismo chega à certeza absoluta do "eu penso" após ter colocado, nos meandros de suas reflexões, tudo em dúvida. Esse método filosófico a que especialistas chamam de "dúvida hiberbólica" pôs por terra, definitivamente, as certezas do pensamento pautado na teologia medieval. Toda ancoragem passa a se apoiar, em Descartes, na razão humana. Com efeito, o declínio da teologia como fundamento da civilização ocidental provoca de imediato a dúvida, postulada e radicalizada por Descartes para dela extrair uma certeza tomada como imediata. No parágrafo 12 da primeira Meditação, o filósofo descreve a seguinte situação: "Suporei, pois, que há não um verdadeiro Deus (...), mas certo gênio maligno, não menos ardiloso e enganador que 0 poderoso, que empregou toda a sua indústria em enganar-me" (DESCARTES, 1983, p. 96). Esse "gênio maligno" aparece, no texto, inscrito no reino do engano, inviabilizando toda e qualquer certeza sobre 0 que quer que fosse.

Esse mundo enganoso exala um odor inequívoco, funcionando como um sintoma do declínio de Deus. Entretanto, tal questionamento em relação à fundação divina não passava de um recurso metodológico para que a existência de Deus fosse, em seguida, restaurada. Cabe enfatizar, porém, que essa restauração é realizada pelo caminho da racionalidade. A divindade passa a ser, nessa lógica, tributária da razão humana. Em outras palavras, esse movimento não parte de Deus, mas chega a ele por um caminho tortuoso, por meio do método da dúvida radical ou hiperbólica. A partir dessa dúvida, Descartes extrai a seguinte certeza imediata: "eu duvido"; ora, se duvidar é pensar, então se eu duvido/penso, logo existo/sou.

Essa noção cartesiana viria a ser filosoficamente desconstruída no último quartel do século XIX, por Friedrich Nietzsche, que ressaltou uma questão até então inédita: a aliança entre gramática, moral e metafísica, expressa no privilégio da estrutura sujeito-predicado. No parágrafo 17 de Além do bem e do mal, o filósofo alemão postula que "algo pensa", mas supor que esse "algo" seja 0 antigo e famoso "eu", mero sujeito da oração, está longe de ser uma "certeza imediata". Para ele, já é inclusive excessivo afirmar que "algo pensa", pois nesse enunciado ainda se mantém o lugar do sujeito (mesmo preenchido por um pronome neutro - em alemão: es). Já se configuraria, na suposta certeza imediata cartesiana, certa interpretação do fenômeno, em lugar do próprio fenômeno. Afinal, segundo Nietzsche, eu não sou o sujeito do meu pensamento; o pensamento me sobrevém e atravessa.

Double $u$, no inglês; double $v$, no francês.

No original, em inglês: Let me call myself, for the present, William Wilson. Optamos, neste artigo, por modificar por vezes as traduções existentes, para nos aproximarmos ainda mais do texto original. 
Voltemos ao cartesianismo. A partir de Descartes, no século XVII, o ser humano passou a ser pensado como a combinação entre elementos materiais e imateriais: 0 sujeito pensante, res cogitans, e o corpo, res extensa. Para Descartes, a essência do homem se encontrava no cogito (alma, razão), desligando-se a inteligência da corporeidade, entendidas como duas "substâncias" distintas e mutuamente excludentes. Cria-se uma violenta cisão entre a res cogitans e a res extensa. 0 segundo elemento (o corpo, a esfera do sensível) não faria senão atrapalhar o primeiro, hierarquicamente superior. 0 problema relacionado à articulação entre esses dois elementos, deixado em aberto por Descartes, será enfrentado por Henri Bergson no final do século XIX. Com efeito, em Matéria e memória, publicado em 1896, Bergson (1999) propõe um novo dualismo, bastante diferente da dicotomia "corpo/alma": trata-se, conforme enunciado no título da obra, da diferença de natureza entre matéria e memória. A estratégia bergsoniana consistiu em reforçar a distinção entre 0 espírito e a matéria, recorrendo à memória tanto para diferenciá-los (como naturezas distintas) quanto para entrelaçá-los na vida efetiva dos homens. Nessa perspectiva filosófica, corpo e alma não mais implicariam uma cisão radical, funcionando, na memória, de modo mutuamente imbricado. A memória entendida bergsonianamente, que, para seu funcionamento, depende da integridade do cérebro, seria o termo de ligação apto a equacionar o velho problema do dualismo legado por Descartes ao pensamento ocidental. Essa questão só foi filosoficamente enfrentada ao final do século XIX.

0 mundo oitocentista herdou, dessa forma, uma noção de sujeito coeso, coerente, seguro, capaz de ter certezas (sobretudo ligadas ao "eu"), pleiteadas, desde Descartes, como imediatas. Embora estejamos deixando de lado as mudanças significativas ocorridas ao longo do século XVIII e as questões colocadas pelo empirismo inglês, privilegiaremos aqui o século XIX, eixo de nossa exploração. Nessa época, assistese a uma fratura na crença acerca da coesão do sujeito. Tal fratura, por sua vez, remete a determinadas condições históricas. As capitais europeias avançadas passam a configurar novos tipos de experiência demarcados pela Revolução Industrial e pela transformação do cotidiano, alavancadas pelo avanço do capitalismo e das inovações técnicas, tais como o crescimento do tráfego urbano, a distribuição de mercadorias produzidas em massa e as novas tecnologias de transporte e comunicação. Essas transformações desembocarão em alterações dos vetores de espaço e de tempo e em novas experiências do corpo e da percepção humana. Com a iluminação pública a gás, por exemplo, um novo mundo noturno, urbano e espectral, também ligado a espetáculos populares de apresentação fantasmática, torna-se o cenário de diversas obras de pintores e escritores modernos, tais como Georges Seurat, E. T. A. Hoffmann, Oscar Wilde, Robert Louis Stevenson, Edgar Allan Poe. É esse universo que se expressa, por exemplo, em um 
conhecido conto de Poe, intitulado "0 homem da multidão" (1840), que sintetiza a nova experiência de multidão, novos regimes de percepção e de atenção, múltipla e fragmentada, bem como 0 gosto pelo enigmático no espaço anônimo.

Encontrava-se em construção, na virada do século XIX ao XX, um tipo de sujeito que seria objeto de investigação de novas disciplinas científicas, fundamentais para a reconfiguração dos contornos da subjetividade moderna. De acordo com Eliane Robert Moraes (2012, p. 100), há uma relação direta entre certo romantismo alemão e os enigmas do inconsciente: 0 assim chamado "grupo de Berlim", do qual Hoffmann fazia parte, explorou intensamente os mistérios da alma, atentos às pesquisas de seus contemporâneos sobre a hipnose, a sugestão, a autoscopia e os fenômenos de alteração de personalidade. Segundo a autora, enquanto no "realismo" do roman noir o horror se manifesta de forma concreta, nas obras do romantismo alemão ele se interioriza, exprime-se destacando ambiguidades inconscientes e angústias alucinantes (MORAES, 2012, p. 100). Nesse contexto, o tema do Duplo tornou-se uma verdadeira obsessão entre os romancistas oitocentistas.

0 Doppelgänger, herdado do romantismo alemão, em especial de uma famosa novela de E. T. A. Hoffmann intitulada $O$ homem da areia (1816), caracteriza-se por uma duplicação da imagem que, por vezes, revela-se como uma sombra obscura, uma cópia perversa, de formas instáveis, distinta de sua "origem", tendendo em geral a destruí-la. Além de Hoffmann, obras como, por exemplo, 0 retrato de Dorian Gray (1890), de 0scar Wilde, 0 médico e o monstro (1886), de Robert Louis Stevenson, e, mais explicitamente, 0 duplo (1846), de Fiódor Dostoiévski, enfatizam o encontro e 0 confronto com o inquietante Duplo, que surge como uma extensão do eu, manifestando forças do inconsciente e sugerindo, por vezes, uma antecipação da morte (MORAES, 2012, p. 101). 0 próprio fato de haver outro "eu", ambiguidades subjetivas, revela perturbações modernas sintomáticas do abalo da crença na firmeza e inteireza da identidade. Abre-se, definitivamente, o mundo do simulacro. É em meio a esses vórtices que surfa o conto de Edgar Allan Poe, intitulado "William Wilson".

Retomemos o nome provisório e fictício do protagonista (e de seu duplo). Além das observações a respeito da repetição inscrita na própria letra $(W)$ e do espelhamento ecoando entre o nome e o sobrenome, ressaltemos uma palavra em inglês cujo som aparece também duplicado nos nomes: will, em português, "vontade". Curiosamente, "vontade" é outra pretensa "certeza imediata" - nesse caso, pleiteada por Arthur Schopenhauer - que, muito influente no pensamento do século XIX, será desconstruída por Nietzsche. No parágrafo 19 de Além do bem e do mal, após o desmonte do cogito cartesiano efetuado nos parágrafos antecedentes, Nietzsche opera uma leitura crítica e demolidora da "vontade" metafísica schopenhaueriana, também deduzida como "certeza imediata". 
Em sintonia com o pensamento da época, no conto de Poe a vontade ocupa um papel central, irrompendo em algumas passagens do texto. Nas páginas iniciais, por exemplo, William Wilson revela ter sido uma criança com vontades próprias, viciado por caprichos os mais selvagens, bem-sucedido ao impor seus desejos à fraqueza de espírito dos pais, que nada faziam a respeito das "más inclinações" do filho (POE, 2008, p. 235). Note-se que, quando descreve a si mesmo, o narrador pouco esconde suas tendências e atos negativos; em nenhum momento busca amenizá-los. Embora William Wilson tenha assumido que seu caráter voluntarioso e despótico seria prejudicial à sua vida, essa observação não aparece como forma de redenção, mas como a constatação de fatos evocados por uma memória póstuma. Ao mesmo tempo, ao atribuir seu mau-caratismo a uma vontade sem freios ou controle educacional, o narrador não deixa de estar atenuando sua responsabilidade sobre o que se torna: eis o regime de ambiguidade em que a narrativa se move. Essa vontade despótica, que se instala no protagonista desde a infância, se radicaliza quando o narrador encontra seu duplo na escola. Este passa a ocupar um lugar central em sua subjetividade, sempre avaliada em relação ao "segundo" William Wilson. Tal noção é reforçada de maneira explícita na seguinte passagem:

Meu caráter ardente, entusiasta e dominador deu-me uma situação preeminente entre meus colegas e, gradualmente, ascendência poderosa sobre todos os que eram mais novos ou da mesma idade que eu; sobre todos, exceto sobre um. Era um aluno que, sem ter comigo qualquer parentesco, tinha o mesmo nome de batismo e o mesmo nome de família, fato este pouco notável, visto que meu nome, apesar de sua nobre origem, era um nome vulgar, um desses nomes que desde tempos imemoriais são também propriedades do povo. Tomei nesta narrativa o nome de William Wilson - nome falso, que não é muito diferente do verdadeiro. Como já disse, só um colega meu, aquele meu homônimo, rivalizava comigo nas lições, nos jogos e nas lutas do recreio; não acreditava nas minhas declarações, assim como não se submetia à minha vontade; recusava, enfim, suportar minha ditadura e manifestava-o sempre que the era possível (POE, 2008, p. 238-239, grifo nosso).

Notemos, de início, que esse nome "falso", mas "não muito diferente do verdadeiro", a um só tempo corrói a equação nome próprio-identidade, instaurando 0 reino do simulacro, e inviabiliza a distinção mesma verdadeiro/falso. Ultrapassa igualmente a oposição entre nobre e vulgar. Quanto ao tema da vontade, ressalte-se que o narrador enfatiza a rivalidade com relação a seu homônimo, o único que não se submete às suas vontades, o espectro que, por vezes, se confunde com a consciência do protagonista - tal como sugere a própria epígrafe do conto, extraída de William Chamberlayne: "Que dirá dela? Que dirá a terrível consciência, esse espectro no meu caminho?" (P0E, 2008, p. 234). Em determinada passagem, por exemplo, William Wilson reconhece que seu rival lhe insinuava conselhos muito superiores à sua idade, sábios e sensatos. Admite, inclusive, que seria um homem melhor e, por isso, mais feliz, se tivesse seguido as recomendações de seu homônimo (POE, 2008, p. 242).

William Wilson e seu duplo eram parecidos em quase todos os aspectos: tinham o mesmo 
nome (falso, mas não distante do verdadeiro) de família e de batismo (nobre e vulgar); nasceram no mesmo dia, possuíam o mesmo peso e altura; entraram e saíram do colégio no mesmo dia. "Se fôssemos irmãos", observa o narrador, "teríamos sido gêmeos" (POE, 2008, p. 239), o que pode nos lembrar a estranheza que irmãos gêmeos provocam em diferentes culturas. Quando 0 duplo nota o quanto esse excesso de similitudes irrita o protagonista, as enfatiza, imitando-0 em gestos e palavras, em sua maneira de se vestir, seu andar, seus modos e, finalmente, sua voz. Contudo, de acordo com o "primeiro" Wilson, seu homônimo possuía uma fraqueza nas cordas vocais que o impedia de falar alto. Por isso, quando falava, sua voz apenas murmurava. Nas palavras do narrador: "Quando eu falava baixo, sua voz dir-se-ia o eco da minha" (POE, 2008, p. 241, grifo do autor).

A associação da voz do duplo ao eco se torna mais significativa quando recordamos o mito de Narciso e Eco, tal como apresentado por Ovídio (1994) em Metamorfoses. Narciso, muito amado por todos, não conseguia se apaixonar. No seu nascimento, Tirésias, o profeta, revelara que, se ele não se conhecesse, viveria até a velhice. Eco, ninfa tagarela, é punida por Juno e condenada a não mais falar, apenas a repetir os últimos sons ouvidos. Apaixonada por Narciso e não correspondida, Eco desfalece, transformandose em pedra e restando apenas a sua voz sussurrante, repetitiva. Certo dia, Narciso encontra-se à beira de um lago, vê a própria imagem e se apaixona, o que o leva à morte. 0 problema do Narciso - aliás, nesse ponto, muito próximo da cultura contemporânea - é estar apaixonado por uma imagem e não poder abraçá-la, não conseguir enlaçá-la, mas apenas projetá-la. Trata-se de um amor impossível. Narciso morre e vira flor.

É interessante notar que a voz do "segundo" William Wilson é descrita como um sussurro, um eco. Como Narciso, o personagem do conto não cria laços com nada ou ninguém, apegando-se à sua própria sombra, à duplicação (por vezes, invertida) de sua imagem. 0 grave problema narcísico, que implica apenas possuir vínculos com um reflexo imagético, intensifica-se no desenrolar do conto, à medida que o protagonista cresce e seu duplo, outrora um personagem com contornos e presença bem definidos, se converte cada vez mais em uma sombra, transformando-se em uma silhueta difusa. Quando ainda eram crianças, 0 homônimo possuía características marcantes e palpáveis, semelhantes às do narrador. 0 "segundo" Wilson passa a imitar o "primeiro" por diversão; em seguida, a fisionomia de ambos torna-se assustadoramente idêntica. Em uma curiosa passagem do conto, o protagonista resolve dirigir-se furtivamente ao quarto do homônimo, em uma noite no final de seu quinto ano de colégio. Ao iluminar o rosto adormecido de seu rival, o que encontra é uma imagem surpreendente:

Seriam realmente aquelas as feições de William Wilson? Sim, eram! Que havia então de extraordinário em seu rosto para que eu me sentisse assim, impressionado? [...] Ele não era assim, 
não. Nunca fora assim, nos momentos em que me contrariava. 0 mesmo nome! Os mesmos traços! A entrada na escola no mesmo dia! $E$ então essa imitação teimosa e absurda de meu andar, de minha voz, de meus hábitos e de meu jeito! Seria humanamente possível, ou o que eu agora contemplava era o resultado do hábito da imitação sarcástica? (POE, 2008, p. 244).

Cabe ressaltar que é precisamente a semelhança que causa estranhamento e perplexidade: 0 mesmo nome, os mesmos traços, a entrada na escola no mesmo dia. 0 outro, mesmo semelhante, é ainda outro "de si mesmo" quando está dormindo. Essa intercambialidade radical entre o estranho e ofamiliar remete ao conceito freudiano do Unheimliche (traduzido como "inquietante familiaridade"). Heim, na língua alemã, significa "lar"; un- é prefixo de negação. Logo, a própria palavra dá pistas sobre o que é inquietante: 0 estranho familiar. 0 estranho é 0 mais próximo; e vice-versa. Em "William Wilson", Poe coloca o leitor nesse lugar da inquietude no qual se instala seu protagonista, ao criar um dispositivo de produção de duplicação e de labirintos. A estrutura do texto impede qualquer leitura definitiva ou conclusões apressadas acerca dos acontecimentos narrados, que se perdem em teias de sentido paradoxais e infinitas, impossibilitando a extração de qualquer verdade. Entramos, em definitivo, no reino do simulacro.

A fim de aprofundar essa leitura, é necessário, neste ponto, explicitar o tema do simulacro em Platão, sobretudo a partir da teoria do conhecimento esboçada no livro VI de $A$ república, e da gradual desqualificação (moral e ontológica) do mimético e do simulacro formulada nos livros seguintes. Em seguida, caberá retomar, de modo breve, a perspectiva aberta no texto "Platão e 0 simulacro", anexado ao livro Lógica do sentido, de Deleuze, e a questão da potência do falso e da máscara em Nietzsche, para então enfatizar de que forma 0 tema do Duplo coloca em xeque 0 modelo identitário de fundo socrático-platônico.

No final do livro VI de A república, Platão elabora o chamado diagrama ou analogia da linha, separando o mundo sensível do mundo inteligível e estabelecendo um sistema hierarquizante para o conhecimento. 0 inteligível refere-se ao mundo transcendente, efetivamente real, das ideias. Já no plano do sensível, impera o reino do falso, do não ser, do engano; em suma, o ponto mais baixo na escala do ser e do conhecimento. Na extrema esquerda dessa linha, no segmento mais afastado do real, encontram-se as imagens. Inseridas nesse grupo, no livro $\mathrm{X}$, a pintura e a poesia serão condenadas por Platão, consideradas como "imitações" do que já não passaria de cópias da essência, isto é, de cópias das cópias, que são as aparências sensíveis. 0 mimético será então duplamente desqualificado: tanto em relação a seu afastamento da realidade inteligível quanto à sua submissão, como cópia degradada, ao puro sensível, sem qualquer compromisso com a verdade, o bem ou o conhecimento verdadeiro. 0 simulacro, produzido pela ficcionalidade, não possuirá qualquer relação com o mundo inteligível, estabelecendo uma ruptura irremediável com 
relação ao modelo de identidade socrático-

platônico: as ideias ou essências imutáveis (cf.

FERRAZ, 1999, p. 73-84).

Em sua instigante leitura, Deleuze (2011, p. 259271) explica de que maneira o conceito platônico de simulacro escapa à lógica da semelhança e da subordinação da diferença às ideias. No texto, o filósofo ressalta que o método da divisão visa a estabelecer a diferença, a distinguir a "coisa" mesma e suas imagens, o original e a cópia, o modelo e o simulacro. Ao separar o puro do impuro, o "bom" do "mau", o projeto platônico teria como objetivo selecionar os rivais, ou seja, selecionar linhagens, distinguindo o autêntico do inautêntico, e não especificar - como será o caso de Aristóteles - ou separar um gênero em espécies definidas. Trata-se de estabelecer a diferença em relação ao Uno, ao Semelhante, à Ideia; mas, uma vez que em Platão não existe um termo mediador, a própria noção de "Mesmo" não pode ser confundida com a identidade de um conceito em geral, caracterizando, antes, a Ideia como sendo a coisa "mesmo". Com efeito, todo o platonismo estaria dominado pela postulação de uma distinção a ser estabelecida entre "a coisa mesma" e os simulacros.

Deleuze parte de uma primeira determinação do motivo platônico: distinguir a essência da aparência, 0 inteligível do sensível, a Ideia da imagem, o original da cópia, o modelo do simulacro. Em seguida, a distinção se desloca entre duas espécies de imagens: as cópias seriam pretendentes bem fundados, garantidos pela semelhança ao modelo; já os simulacros equivaleriam aos falsos pretendentes, construídos a partir de uma dissimilitude fundamental. Passa a ser necessário distinguir as boas cópias das más cópias. Em seguida, o autor afirma que Platão separa 0 campo das imagens da seguinte forma: de um lado, estariam as "cópias-ícones" e, de outro, os "simulacros-fantasmas" (DELEUZE, 2011, p. 262). A motivação do filósofo grego seria, em suma, a de selecionar os pretendentes, distinguindo as boas das más cópias, cópias bem fundadas e simulacros, estes caracterizados pela dessemelhança. Para Deleuze, o método platônico da divisão visa a assegurar o triunfo das cópias sobre os simulacros.

Entre os três termos platônicos - Ideia, cópia e simulacro -, existe uma escala descendente; no entanto, a relação entre eles não deve ser pensada de modo simétrico. Entre Ideia e cópia, há uma relação de semelhança, o que garante a existência de "boas cópias", tais como as do artesão que fabrica mesas ou camas a partir do modelo abstrato e incorruptível da ideia de mesa ou de cama. Entre a Ideia e o simulacro, entretanto, instaura-se uma não relação, uma imagem sem semelhança, rompendo-se qualquer liame com o modelo. De acordo com Deleuze (2011, p. 263), o simulacro é construído sobre uma disparidade ou diferença; ele interioriza uma dissimilitude. Se o simulacro possui um modelo, na perspectiva deleuzeana, trata-se de um outro modelo, de um modelo do Outro, decorrente de uma dessemelhança interiorizada. 
Para explorar o modelo do Outro, Deleuze (2011, p. 268) alia-se ao tema do falso - Pseudos - como potência em Nietzsche, citando o motivo da "mais alta potência do falso". Para o filósofo francês, no pensamento de Nietzsche a subversão do platonismo implica a emergência do simulacro, fazendo cair sob a potência do falso (fantasma) o Mesmo e o Semelhante, o modelo e a cópia. Esclarece, ainda, que não se trata de um novo fundamento, pois o falso, em sua mais alta potência, engole todo fundamento, assegura um universal desabamento (effondrement), como "acontecimento positivo e alegre", como effondement. Esse a-fundamento (effondement) é tematizado pelo autor, em Diferença e repetição, como uma liberdade do fundo não mediatizado, a descoberta de um fundo por trás de todo outro fundo, a relação do sem-fundo com o não fundado (DELEUZE, 1968, p. 92). A inspiração nietzschiana é explicitada na sequência da citação anterior, extraída de "Platão e o simulacro", quando a seguinte passagem de Além do bem e do mal (parágrafo 289) é retomada por Deleuze:

Por trás de uma caverna, uma caverna ainda mais profunda - um mundo mais rico, mais estranho e mais vasto além de uma superfície, um abismo (Abgrund) por trás de cada chão/razão (Grund), por trás de toda "fundamentação" (Begründung) (NIETZSCHE, 2012, p. 216, tradução modificada).

A referência nietzschiana à metáfora da caverna nada possui de inocente. A retomada da famosa alegoria da caverna, que abre 0 livro VII de $A$ república, remete imediatamente ao diagrama ou à analogia da linha em que Platão ancora sua teoria do conhecimento. Em "Das três imagens de filósofos", inserido no livro Lógica do sentido, Deleuze (2011, p. 131) afirma que a imagem do filósofo parece ter sido fixada pelo platonismo: um ser que ascende, que sai da caverna e que, quanto mais alto se eleva em direção às nuvens, mais se purifica. Se a caverna de Platão aponta para uma ascese em direção à purificação e à verdade, a caverna nietzschiana esposa um movimento de mise en abyme, um recurso artístico capaz de recuar ao infinito qualquer suposto fundo, inviabilizando a instauração de supostos "fundamentos". Nessa perspectiva, apenas existem outros fundos, fundos falsos, projetando-se em abismo, produzindo novas reviravoltas que inviabilizam qualquer chão (Grund) para ancorar certezas, assentar a razão e assegurar a crença na inteireza e firmeza das identidades (FERRAZ, 2002, p. 133-149).

Ora, não seria o Duplo, na esteira do simulacro, um dispositivo labiríntico e infinito de produção de vertigens e paradoxos? 0 modelo do Duplo escapa da ideia do Mesmo, do Uno e da teoria do conhecimento proposta por Platão, adentrando o reino das incertezas e das múltiplas identidades. Nesse sentido, o aparente "dois" implicado na figuração do Duplo transcende, a rigor, dualismos, acionando um infinito labiríntico de duplicações em série. No conto de Poe, foi através de um "verdadeiro labirinto, de estreitos corredores" no estranho colégio que Wilson, pela primeira vez, viu no outro projetada sua própria identidade (POE, 2008, p. 243). Porém, lembremos que o segundo 
William Wilson ganha novas descrições à medida que o protagonista cresce e se rende aos vícios e às extravagâncias. A identidade do duplo se torna mais ambígua e incerta, paradoxal e múltipla. 0 que antes parecia ser fixo, mesmo nesse outro, torna-se, no decorrer do conto, cada vez mais sombra e espectro:

Havia qualquer coisa de sobrenatural em seus modos, no tremor nervoso do seu dedo erguido entre meus olhos e a luz, que me enchia de completo assombro. A importância e a solenidade repreensiva que suas palavras surdas e sibilantes continham, o modo, o timbre, a chave daquelas sílabas simples, familiares, mas segregadas em mistério, fizeram-me estremecer, como se minha alma se tivesse produzido a descarga de uma pilha elétrica. Durante alguns momentos, o espanto e o terror paralisaram-me 0 cérebro; quando voltei a mim, ele desaparecera (POE, 2008, p. 245-246).

Nessa passagem, descrita após uma noite de orgia e devassidão, o duplo surge e desaparece de maneira misteriosa, marcando presença por sua voz sussurrante. Essa situação ocorre novamente em 0xford, enquanto o protagonista tentava arrancar dinheiro de um jovem rico, em um jogo de cartas, por meio de truques ilícitos. Embora o duplo surja com as mesmas roupas e tenha a mesma estatura de seu homônimo, seu rosto nunca mais se define, fugindo à apresentação mimética. A certeza de que era o duplo que destruía sua reputação por toda a Europa leva Wilson a um confronto final com o estranho espectro. Esse último encontro acontece, significativamente, em um baile de máscaras. Lembremos que o tema da máscara em Nietzsche também corresponde à ruína do modelo de identidade platônico e opera na lógica do Duplo e do simulacro. Dediquemo-nos, a seguir, brevemente ao tema, retomando, mais uma vez, as teses de Platão.

A desqualificação da máscara está relacionada à condenação do mimético e à invenção do polo de oposições metafísicas que balizam a filosofia socrático-platônica. Para fundar esse campo, Platão rivalizou com seus adversários mais imediatos na polis grega - a sofística e a retórica, a poesia e a pintura -, utilizando uma tática que consistiu em colocá-las em estreita relação umas com as outras, para que determinada crítica a respeito de uma recaísse sobre todas as demais. As oposições forjadas - essência/ aparência, verdadeiro/falso, ser/parecer -, além de consolidarem a lógica da contradição, circunscrevem as práticas discursivas condenadas no campo do falso, da mentira, do não ser, do engano, capazes de persuadir, de adular os sentidos, de modo totalmente descompromissado com a verdade. Afinal, desse momento em diante, o reino do falso será associado a uma noção de pseudos posta em oposição ao "verdadeiro" (alethes), tornado objeto exclusivo da filosofia.

Conforme denunciado por Nietzsche, esse gesto revela que metafísica e moral estão intimamente relacionadas: práticas associadas ao terreno da ficcionalidade, do não sério, do fingimento passam a ser consideradas forças sedutoras aptas a desviar do caminho da ascese em direção 
ao Bem e à Verdade. A máscara será associada ao fingimento, inserida no reino do mimético e do simulacro. Essas acusações de cunho moral e ontológico (as imagens são as mais distantes do real, do ser) se evidenciam no deslocamento de sentido da palavra hypokrites: utilizada em grego para designar 0 ator (que usava máscaras), nas línguas latinas modernas passou a nomear aquele que mente, o que finge, fazendo-se passar por virtuoso. 0 uso de máscaras passa a remeter ao ocultamento de uma verdade "por trás" (cf. FERRAZ, 2002, p. 117-122).

A aposta na potência do falso e do simulacro inaugura um regime que se esquiva à pretensão de alcançar um suposto "fundo", abrindo-se caminhos para o movimento de mise en abyme. Nesse novo regime, por trás das máscaras há sempre outras máscaras, ao infinito. Como bem detectaram o filósofo Emerson, Nietzsche e, em certa medida, também Poe, as máscaras colocadas não podem ser retiradas sem que se arranque junto o que se julgava ser o rosto autêntico.

Embora os encontros entre Wilson e seu rival, após a saída do colégio, tenham sido marcados pelo ocultamento do rosto do homônimo, criandose um mistério em torno de seu semblante duplicado, a retirada da máscara na cena do encontro final no baile apenas revela uma imagem difusa e eleva incertezas e ambiguidades à sua mais alta potência. No baile de máscaras, 0 confronto acontece quando o protagonista desiste de perseguir a esposa do anfitrião para enfrentar o duplo, que vestia, como ele, um manto de veludo azul, uma espada suspensa na cintura e uma máscara de seda preta.

Nos momentos finais do conto, tudo ocorre de forma confusa e paradoxal, tanto para o leitor quanto para o narrador/protagonista. Wilson e 0 duplo dirigem-se para uma sala na qual a luta ocorre com a porta trancada. Em poucos minutos, o protagonista afirma ter encurralado seu rival na parede e, vendo-0 preparado para defender-se, trespassa-lhe 0 peito sucessivas vezes. Em seguida, a fechadura da porta se move e, rapidamente, Wilson vai até ela para impedir a entrada de algum intruso. Quando ele volta ao inimigo agonizante, algo espantoso acontece: "No lugar onde momentos antes eu nada vira, havia agora um grande espelho (pelo menos assim me pareceu, em minha exaltação)" (POE, 2008, p. 253 , grifo nosso). Eis o que conta o narrador, aproximando-se do estranho objeto e nele vendo caminhar, em sua direção, sua própria imagem, com o rosto pálido e sujo de sangue, avançando com passos lentos e vacilantes. Contudo, para Wilson, essa cena teria sido ilusória:

Disse ser isso que se me afigurou, mas, na realidade, nada disso ocorria. Tratava-se do meu inimigo, de William Wilson, que, agonizante, se erguia perante mim. A máscara e o manto jaziam no chão. Não havia uma só peça em seu traje nem um só traço em seu rosto (tão característico e tão singular) que não fossem meus; realizava 0 absoluto na identidade! (POE, 2008, p. 253).

A entrada do espelho opera a radicalização do movimento vertiginoso do simulacro e das 
máscaras. Lembremos que a metáfora do espelho foi se arraigando no mundo ocidental, em densas camadas de sentido superpostas. Muitos desses sentidos foram remetidos a modelos de identidade, a formas de constituir 0 "eu" em relação ao olhar do outro, mas também a regimes de introspecção reflexiva e ao jogo mimético. Vale lembrar uma frase muito citada de Stendhal, colocada em epígrafe ao capítulo 13 do livro 0 vermelho e o negro (1830): "Um romance é um espelho que se passeia pelo caminho". ${ }^{3}$ De fato, durante 0 século XIX, boa parte da ficção propôs espelhos romanescos - ainda que deformantes - da sociedade ocidental moderna (cf. FERRAZ, 2015, p. 121-122).

No caso do conto de Poe, é interessante notar a vertigem causada pelo jogo de espelhos, que deforma a imagem do protagonista, sua suposta identidade e torna ainda mais paradoxal 0 confronto com o duplo. Esse elemento aparece e desaparece de maneira repentina: o protagonista pensa ter visto um grande espelho refletindo sua imagem no local onde, antes, deitara seu inimigo ferido; porém, esse objeto é depois considerado como ilusório e substituído por outra imagem inexata. Com a máscara e a capa caídas no chão, 0 narrador mira o rosto supostamente desvelado de seu inimigo; surpreende-se, no entanto, ao reconhecer seus próprios traços, chegando a dizer que até mesmo a identidade do rival era a sua. ${ }^{4}$ Ora, se existem duas identidades, se por trás da máscara existe a face de um outro oscilante e indecidível, já não é mais possível pensar no modelo do Uno, do Mesmo e da Verdade. Introduz-se, a seguir, na narrativa outro momento vertiginoso que desestabiliza em definitivo qualquer certeza que um leitor pouco ruminante poderia ter a respeito do desfecho. Citemos, por fim, a cena final do conto:

Era Wilson, mas um Wilson que já não murmurava ao falar! Pelo contrário, falava tão alto que tive a impressão nítida de ouvir a minha própria voz dizendo:

- Venceste e eu pereço. Mas daqui para frente também tu estarás morto. Morreste para 0 mundo, para o céu e para a esperança! Existias em mim. Olha bem para a minha morte, e nessa imagem, que é a tua, verás o teu próprio suicídio! (POE, 2008, p. 253). ${ }^{5}$

Nessa passagem, ocorrem três transformações: o que ele julgava ser 0 espelho revela-se como 0 seu homônimo; a seguir, este outro passa a ser o espelho dele mesmo. 0 duplo não mais possuía a característica marcante do sussurro, mas falava alto e com um tom que confundiu o "primeiro" Wilson, que chega a pensar ouvir sua própria voz.

No original, em francês: Un roman: c'est um miroir qu'on promène le long du chemin.

No original, em inglês: Not a thread in all his raiment - not a line in all the marked and singular lineaments of his face which was not, even in the most absolute identity, mine own! (POE, 2014, p. 20, grifo nosso)

No original, em inglês, o trecho é ainda mais labiríntico: It was Wilson; but he spoke no longer in a whisper, and I could have fancied that I myself was speaking while he said: "You have conquered, and I yield. Yet, henceforward art thou also dead - dead to the World, to Heaven and to Hope! In me didst thou exist - and, in my death, see by this image, which is thine own, how utterly thou hast murdered thyself" (POE, 2014, p. 20). 
0 problema narcísico de desejar uma imagem aparece de modo explícito nos momentos finais, quando esse confronto imagético culmina na morte. Contudo, morte de quem? De quem é a voz na fala final? Se o duplo de Wilson morre, carregando consigo seu homônimo - como parece sugerir a passagem -, quem narra 0 conto? A impossibilidade de responder a essas perguntas ou de tirar qualquer conclusão a esse respeito coloca o leitor no vórtice do turbilhão voraz produzido pelo movimento textual. Tratase de uma ficção que põe em funcionamento a vertiginosa e labiríntica lógica da mise en abyme, tanto como objeto de narração quanto como jogo do próprio narrar.

0 exercício de ruminação proposto neste artigo a respeito da crise do modelo de identidade no período moderno também fornece algumas pistas acerca dos novos modos de configuração do "eu" na sociedade ocidental contemporânea. Cada vez mais evidencia-se, na atualidade, certo declínio de uma subjetividade escavada nas profundezas da interioridade psicológica balizada pelo desejo, tão bem investigada por Michel Foucault no final dos anos 1970. Naquela época, o regime da "autenticidade", salientado por Richard Sennett, era baseado na crença de que a própria personalidade seria vivenciada como um tesouro interior que se trai em sua apresentação pública. Nesse regime, as máscaras sociais esconderiam um rosto autêntico e "verdadeiro", que deveria ser protegido do olhar de estranhos. É também nesse sentido que o conto de Poe põe em xeque 0 dualismo ser/parecer e corrói a dicotomia rosto/ máscara, heranças platônicas do 0cidente tão caras ao período moderno. 0 topos do Duplo coloca sob o olhar atento a suspeição da coerência e da unidade do eu, a crença em valores eternos e em essências imutáveis.

Com 0 declínio da cultura letrada - articulado à ascensão da cultura do espetáculo e da imagem -, as palavras, a leitura e a interpretação veem ameaçadas sua antiga potência. Como enfatizou Guy Debord em 1967, no livro-manifesto $A$ sociedade do espetáculo, as relações consigo e com o outro passaram a ser cada vez mais mediadas por imagens. Nesse universo, "ser" confunde-se com "ser visto"; segundo a mesma lógica, o que é bom aparece, e o que não aparece não é bom ou sequer existe. Na sociedade do espetáculo, não apenas as palavras orais e escritas são esmagadas por uma avalanche de imagens que se revezam nas telas; o próprio mundo é transformado nessas imagens.

Conforme identifica Paula Sibilia (2008, p. 233), hoje a principal obra que produzem os autores-narradores-protagonistas no mundo cibernético é o próprio "eu", em um movimento que cria a recria a personalidade. Trata-se de uma subjetividade visível, orientada para e pelos outros. Quebram-se os espelhos introspectivos, dando lugar a um outro plasmado nas telas midiáticas e nos ciberespelhos (FERRAZ, 2015, p. 115-133). Em vez do jogo entre interioridade e máscaras sociais, entram em cena novos reflexos especulares e espetaculares. Retornando ao tema 
do Duplo e ao século XIX, podemos observar certas transformações e mudanças ainda em curso em relação à forma de se relacionar com as imagens, com o outro e, sobretudo, com esse outro inquietantemente familiar, esse estranho que se autonomeia: "eu".

\section{Referências}

BERGSON, Henri. Matéria e memória. São Paulo:

Martins Fontes, 1999.

DEBORD, Guy. A sociedade do espetáculo. Rio de Janeiro: Contraponto, 2012.

DELEUZE, Gilles. Platão e o simulacro. In.: Lógica do sentido. São Paulo: Perspectiva, 2011.

Différence et répétition. Paris: PUF, 1968.

DESCARTES, René. Meditações. São Paulo: Abril

Cultural, 1983.

FERRAZ, Maria Cristina Franco. Ruminações: Cultura letrada e dispersão hiperconectada. Rio de Janeiro: Garamond, 2015.

Homo deletabilis - corpo, percepção, esquecimento: do século XIX ao XXI. Rio de Janeiro: Garamond/FAPERJ, 2010.

Platão: As artimanhas do fingimento. Rio de Janeiro: Ediouro, 2009.

. Nove variações sobre temas

nietzschianos. Rio de Janeiro: Relume Dumará, 2002.

FOUCAULT, Michel. História da sexualidade I. Rio de Janeiro: Edições Graal, 2013.

MORAES, Eliane Robert. 0 corpo impossível. São

Paulo: Iluminuras, 2002.

NIETZSCHE, Friedrich. Além do bem e do mal.

Petrópolis, RJ: Editora Vozes, 2012.
Genealogia da moral. São Paulo:

Companhia das Letras, 2009.

Gaia ciência. São Paulo: Companhia das

Letras, 2012.

OVÍDIO. Les métamorphoses. Paris: Société d.édition Les Belles Lettres, 1994.

PLATÃO. A república. Lisboa: Calouste Gulbenkian, 1990.

P0E, Edgar Allan. William Wilson. South Australia: University of Adelaide, 2014. . William Wilson. In.: Histórias extraordinárias. São Paulo: Companhia das Letras, 2008 .

SENNETT, Richard. 0 declínio do homem público. Rio de Janeiro: Record, 2014.

SIBILIA, Paula. 0 show do eu. Rio de Janeiro: Nova Fronteira, 2008. 


\section{The double, image and simulacra:} Edgar Allan Poe's "William Wilson"

\section{Doble, imagen y simulacro: "William Wilson" de Edgar Allan Poe}

\section{Abstract}

Edgar Allan Poe's short story "William Wilson" develops the theme of the Double, also known as Doppelgänger. This article investigates the tale's motif and its implications concerning the questions of subjectivity and image in the XIXth century. The modern obsession with the evil shadows resonates some uncertainties introduced in European thought, such as the crisis of the identity model inherited from Platonism, the human figure's deformation, the emergence of psychoanalysis. In short, it highlights the threat of the corrosion of the self's supposed unity. It relates this topic to Deleuze's and Nietzsche's anti-metaphysical perspectives on the simulacra and the mask and analyses some passages of Poe's tale which emphasizes the "power of the false" and suspends some Platonic inheritances.

\section{Keywords}

Double. Simulacra. Anti-metaphysical philosophy.

\section{Resumen}

A partir de la historia "William Wilson" de Edgar Allan Poe, el presente artículo explora el tema del doble y sus desarrollos en el campo de la subjetividad y la imagen durante el siglo XIX. La obsesión con las sombras del mal en la época moderna refleja algunas incertidumbres introducidas en el pensamiento europeo, como la crisis del modelo de identidad heredado del platonismo, la deformación del hombre, la aparición del psicoanálisis. Evidencia, en suma, la fuerza de la amenaza a la cohesión del yo. El artículo relaciona este tema las perspectivas antimetafísicas del simulacro y de la máscara propuestas por Deleuze y Nietzsche, además de analizar algunos pasajes del cuento de Poe, que enfatizan la "potencia de lo falso" y suspenden algunas herencias platónicas del mundo occidental.

\section{Palabras clave}

Doble. Simulacro. Filosofía antimetafísico. 


\section{Expediente}

A revista E-Compós é a publicação científica em formato eletrônico da Associação Nacional dos Programas de Pós-Graduação em Comunicação (Compós). Lançada em 2004, tem como principal finalidade difundir a produção acadêmica de pesquisadores da área de Comunicação, inseridos em instituições do Brasil e do exterior.

\section{E-COMPÓS I www.e-compos.org.br I E-ISSN 1808-2599}

Revista da Associação Nacional dos Programas de Pós-Graduação em Comunicação.

Brasília, v.19, n.1, jan./abr. 2016.

A identificação das edições, a partir de 2008, passa a ser volume anual com três números.

Indexada por Latindex I www.latindex.unam.mx

\section{CONSELHO EDITORIAL}

Alexandre Farbiarz, Universidade Federal Fluminense, Brasil Alexandre Rocha da Silva, Universidade Federal do Rio Grande do Sul, Brasil Ana Carolina Damboriarena Escosteguy, Pontifícia Universidade Católica do Rio Grande do Sul, Brasil

Ana Carolina Rocha Pessôa Temer, Universidade Federal de Goiás, Brasil Ana Regina Barros Rego Leal, Universidade Federal do Piaú, Brasil Andrea França, Pontifícia Universidade Católica do Rio de Janeiro, Brasil André Luiz Martins Lemos, Universidade Federal da Bahia, Brasil Antonio Carlos Hohlfeldt, Pontifícia Universidade Católica do Rio Grande do Sul, Brasil

Arthur Ituassu, Pontifícia Universidade Católica do Rio de Janeiro, Brasil Álvaro Larangeira, Universidade Tuiuti do Paraná, Brasil

Ângela Freire Prysthon, Universidade Federal de Pernambuco, Brasil César Geraldo Guimarães, Universidade Federal de Minas Gerais, Brasil Cláudio Novaes Pinto Coelho, Faculdade Cásper Líbero, Brasil Daisi Irmgard Vogel, Universidade Federal de Santa Catarina, Brasil Denize Correa Araujo, Universidade Tuiuti do Paraná, Brasil Eduardo Antonio de Jesus, Pontifícia Universidade Católica de Minas Gerais, Brasil

Daniela Zanetti, Universidade Federal do Espirito Santo, Brasil Eduardo Vicente, Universidade de São Paulo, Brasil Elizabeth Moraes Gonçalves, Universidade Metodista de São Paulo, Brasil Erick Felinto de Oliveira, Universidade do Estado do Rio de Janeiro, Brasil Francisco Elinaldo Teixeira, Universidade Estadual de Campinas, Brasil Francisco Paulo Jamil Almeida Marques, Universidade Federal do Paraná, Brasil

Gabriela Reinaldo, Universidade Federal do Ceará, Brasil Goiamérico Felício Carneiro Santos, Universidade Federal de Goiás, Brasil Gustavo Daudt Fischer, Universidade do Vale do Rio dos Sinos, Brasil Herom Vargas, Universidade Municipal de São Caetano do Sul, Brasil Itania Maria Mota Gomes, Universidade Federal da Bahia, Brasil
Janice Caiafa, Universidade Federal do Rio de Janeiro, Brasil Jiani Adriana Bonin, Universidade do Vale do Rio dos Sinos, Brasil José Afonso da Silva Junior, Universidade Federal de Pernambuco, Brasil José Luiz Aidar Prado, Pontifícia Universidade Católica de São Paulo, Brasil Juçara Gorski Brittes, Universidade Federal de Ouro Preto, Brasil Kati Caetano, Universidade Tuiuti do Paraná, Brasil Lilian Cristina Monteiro França, Universidade Federal de Sergipe, Brasil Liziane Soares Guazina, Universidade de Brasilia, Brasil Luíza Mônica Assis da Silva, Universidade de Caxias do Sul, Brasil Luciana Miranda Costa, Universidade Federal do Pará, Brasil Malena Segura Contrera, Universidade Paulista, Brasil Maria Ogécia Drigo, Universidade de Sorocaba, Brasil Maria Ataide Malcher, Universidade Federal do Pará, Brasil Marcia Tondato, Escola Superior de Propaganda e Marketing, Brasil Marcel Vieira Barreto Silva, Universidade Federal da Paraíba, Brasil Maria Clotilde Perez Rodrigues, Universidade de São Paulo, Brasil Maria das Graças Pinto Coelho, Universidade Federal do Rio Grande do Norte, Brasil

Mauricio Ribeiro da Silva, Universidade Paulista, Brasil

Mauro de Souza Ventura, Universidade Estadual Paulista, Brasil Márcio Souza Gonçalves, Universidade do Estado do Rio de Janeiro, Brasil Micael Maiolino Herschmann, Universidade Federal do Rio de Janeiro, Brasil Mirna Feitoza Pereira, Universidade Federal do Amazonas, Brasil Nísia Martins Rosario, Universidade Federal do Rio Grande do Sul, Brasil Potiguara Mendes Silveira Jr, Universidade Federal de Juiz de Fora, Brasil Regiane Regina Ribeiro, Universidade Federal do Paraná, Brasil Rogério Ferraraz, Universidade Anhembi Morumbi, Brasil Rose Melo Rocha, Escola Superior de Propaganda e Marketing, Brasil Rozinaldo Antonio Miani, Universidade Estadual de Londrina, Brasil Sérgio Luiz Gadini, Universidade Estadual de Ponta Grossa, Brasil Simone Maria Andrade Pereira de Sá, Universidade Federal Fluminense, Brasil Veneza Mayora Ronsini, Universidade Federal de Santa Maria, Brasil Walmir Albuquerque Barbosa, Universidade Federal do Amazonas, Brasil

\section{COMISSÃO EDITORIAL}

Cristiane Freitas Gutfreind, Pontifícia Universidade Católica do Rio Grande do Sul, Brasil Irene Machado, Universidade de São Paulo, Brasil

Eduardo Antonio de Jesus, Universidade Católica de Minas Gerais, Brasil

\section{CONSULTORES AD HOC}

Cleusa M. Andrade Scroferneker, Pontifícia Universidade Católica do Rio Grande do Sul, Brasil Francisco Rüdiger, Pontifícia Universidade Católica do Rio Grande do Sul, Brasil Juliana Freire Gutmann, Universidade Federal da Bahia, Brasil Karla Regina M. P. Patriota Bronsztein, Universidade Federal de Pernambuco, Brasil Laura Loguercio Cánepa, Universidade Anhembi Morumbi, Brasil Lucia Isaltina C. Leão, Pontifícia Universidade Católica de São Paulo, Brasil

\section{EQUIPE TÉCNICA}

\section{ASSISTENTE EDITORIAL I Márcio Zanetti Negrini}

REVISÃO DE TEXTOS I Press Revisão

EDITORAÇÃO ELETRÔNICA I Roka Estúdio

CONTATO I revistaecompos@gmail.com
COMPÓS I www.compos.org.br

Associação Nacional dos Programas de Pós-Graduação em Comunicação

Presidente

Edson Fernando Dalmonte

Programa de Pós-Graduação em Comunicação

e Cultura Contemporânea - UFBA

edsondalmonte@uol.com.br

Vice-presidente

Cristiane Freitas Gutfreind

Programa de Pós-Graduação em Comunicação Social - PUC-RS cristianefreitas@pucrs.br

Secretário-Geral

Rogério Ferraraz

Programa de Pós-Graduação em Comunicação

Universidade Anhembi Morumbi

rogerioferraraz@anhembimorumbi.edu.br 